\title{
QUALITY EVALUATION OF POTATO AND VEGETABLE CRISPS IN LATVIAN MARKET
}

\author{
Ilze Kalnina, Evita Straumite, Zanda Kruma, Martins Sabovics, Tatjana Kince \\ Latvia University of Agriculture \\ kalnina_ilze@yahoo.com
}

\begin{abstract}
Salty snacks are popular appetizers consumed between meals and are one of favourite components of menu at different social gatherings and private celebrations. Consumers base their choice of snacks not only on flavour and smell of product, but also on different kinds of parameters like colour, texture and nutritional value as well as other information labelled on packaging. Typically salty snacks are associated with potato (Solanum tuberosum) crisps, but in present paper there were viewed also vegetable crisps and snacks. The aim of this research was to evaluate nutritional value and physical quality of potato and vegetable crisps and wholegrain snacks in Latvian market. From January to March 2017, 22 potato and vegetable crisps and wholegrain snack samples from Latvian market were analysed. For all samples, information on the labels was analysed as well as salt content, thickness, crispness and colour using standard methods. For $31.8 \%$ of the investigated samples, presented information on label and determined salt content do not differ significantly $(\mathrm{p}>0.05)$. That means that $68.2 \%$ of the analysed potato, vegetable crisps and snacks on the packaging labels have represented incorrect salt content. Positive moderate correlation $(r=0.489)$ between potato and vegetable crisps thickness and crispness was found out. Raw materials and ingredients of samples directly impact colour values. If a sample contains beetroot, the colour results would indicate dark red. All potato crisps colour values point out light yellow colour.
\end{abstract}

Key words: potato and vegetable crisps, salt content, quality.

\section{Introduction}

Potato (Solanum tuberosum) crisps are well known as salty snacks, which make an essential part of the snack market not only in Latvian market, but also in many other countries. Potato crisps are thin slices of potato, which have been deep fried or baked. They can be used like snack, side dish or appetizer (Salvador et $a l ., 2009)$. Lately vegetable crisps and other similar snacks like wholegrain, crisp spelt (Triticum spelta), corn (Zea mays) and potato based snacks have become very popular and have grown into significant competitors. The most important quality indicators for crisps are flavour, smell, colour and also texture or crispness. Colour is seriously assessed by consumers and can be one of their main reasons for selecting or rejecting crisps (Mendoza, Dejmek, \& Aguilera, 2007). Colour of crisps is impacted by several causes - potato and vegetable type, natural defect in raw products (black spots), frying process, used oil, seasonings. Amount of absorbed oil also in post-frying process can turn colour of crisps darker and even leave oily spots on their surfaces (Mendoza, Dejmek, \& Aguilera, 2007). Therefore, overall assessment of crisp colour includes colour itself, quantity, shape, allocation and intertwining of the small details distributed on crisps (Romani et al., 2009).

Crispness and crunchiness are terms frequently used to characterize texture of crisps. These crunchy and crispy attributes are important factors on which consumers set up their evaluation of crisps (Salvador et al., 2009). Crispness is not only relevant for crisps but it also makes essential impact on total consumer's appreciation level for every kind of food products. The contribution of texture of product has been studied for more than 50 years and main conclusions are that crispness is a complex group of attributes resulting from both multiple sensations and multiple physical indicators, uniting molecular, structural and production processes, and also storage conditions (Roudaut et $a l .$, 2002). Texture of crisps is also affected by type of oil used for frying and frying temperature (Kita, Lisińska, \& Gołubowska, 2007). Efforts have been made to measure crispness of product and there are developed several techniques, one of the most popular is a puncture test using a cylindrical probe, where fracture force suggests level of crispness (Pedreschi, Segnini, \& Dejmek, 2004), studies show that there is strong correlation between magnitude of force drop and the level of crispness (Vincent, 1998), force and hardness measure the power for breaking, the power and these mechanical tests can be used to rate and compare crispness of product (Rojo \& Vincent, 2009), but for confirmation of this correlation, it is suggested taking into account also acoustic measurements, sounds transmitted when crisp breaks (Taniwaki \& Kohyama, 2012).

Salt content and reduction of salt consumption is popular discussion object for scientific community and overall society because raised salt (sodium chloride) intake can lead to different health problems and diseases. It is proven that even small reduction of salt in dietary, would grant considerable health improvement (Bibbins-Domingo et al., 2010). That is why, based on recent studies, the WHO strongly recommends decrease of sodium dietary intake to less than 2 grams per day (less than 5 grams of salt per 
day) for adults (WHO, 2012). It is possible to reduce amount of sodium in processed foods by applying different strategies, and in result there are not any losses of salty taste (Mueller, Koehler, \& Scherf, 2016). So it is important to remind the public that salt reduction is advisable and necessary for both consumers and manufacturers. A great way to keep track of product's quality indicators is nutrition information on food labels. Although nutrition information is useful, studies show that understanding this it is one thing, but using it to make healthier choices is completely other (Grunert, Wills, \& Fernández-Celemín, 2010).

The aim of this research was to evaluate nutritional value and physical quality of potato and vegetable crisps and wholegrain snacks in Latvian market.

\section{Materials and Methods}

Samples

In the research from January till March 2017 different potato and vegetable crisps and wholegrain snacks available in Latvian market were analysed. The abbreviations of analysed potato crisps (16 samples), vegetable crisps (2 samples) and snacks (4 samples) shown in Table 1 will be used in the further text. In Table 1, there is also shown information from crisp labels per $100 \mathrm{~g}$ - salt, fat, saturated fat content and energy value. All samples were in original packaging and kept at room temperature $\left(2{ }^{\circ} \mathrm{C}\right)$, and each selection of samples for testing was in similar size. Crisps were evaluated immediately after opening the packaging.

\section{Determination of salt content}

The salt content of crisps samples was determined using Vardavas et al. modified Mohr method (1981) (Vardavas et al., 2007). Fine ground sample (2.000 \pm $0.010 \mathrm{~g}$ ) was dissolved in $100 \mathrm{~mL}$ of distilled water. One millilitre of $5 \% \mathrm{~K}_{2} \mathrm{CrO}_{4}$ solution was added and titration performed with $0.1 \mathrm{M} \mathrm{AgNO}_{3}$ solution to the first appearance of an orange colour. Calculation of salt

The abbreviation and nutrition information of samples used in the research

Table 1

\begin{tabular}{|c|c|c|c|c|c|}
\hline \multirow{2}{*}{ Sample } & \multirow{2}{*}{ Brand } & \multicolumn{3}{|c|}{ Nutritional information, g $100 \mathrm{~g}^{-1}$} & \multirow{2}{*}{$\begin{array}{c}\text { Energy value, } 100 \mathrm{~g}^{-1} \\
\mathrm{~kJ}\end{array}$} \\
\hline & & Salt & Fat & Saturated fat & \\
\hline \multicolumn{6}{|c|}{ Potato crisps } \\
\hline KC_1 & The Original Taffel Snacks & 1.0 & 32.0 & 3.3 & 2254.0 \\
\hline KC_2 & Lorenz Snack-World & 2.0 & 32.0 & 2.5 & 2189.0 \\
\hline KC_3 & Adazu Istie Cipsi & 1.4 & 25.0 & 1.8 & 1944.0 \\
\hline KC_4 & Lay's & 2.0 & 30.0 & 10.0 & 2139.0 \\
\hline KC_5 & Adazu Istie Cipsi & 1.6 & 32.0 & 14.0 & 2222.0 \\
\hline KC_6 & Estrella & 1.8 & 33.0 & 15.0 & 2203.0 \\
\hline KC_7 & Rimi & 1.5 & 36.0 & 16.0 & 2255.0 \\
\hline KC_8 & Rimi & 1.2 & 32.0 & 15.0 & 2245.0 \\
\hline KC_9 & Pringles & 1.4 & 33.0 & 3.4 & 2161.0 \\
\hline KC_10 & Estrella & 1.9 & 33.0 & 15.0 & 2194.0 \\
\hline KC_12 & Trafo Bio-Organic Snacks & 2.0 & 37.0 & 3.5 & 2247.0 \\
\hline KC_13 & Lisa's Kartoffel-Chips & 1.2 & 28.7 & 3.4 & 2116.0 \\
\hline KC_14 & Biona Organic & 1.2 & 37.0 & 3.5 & 2247.0 \\
\hline KC_17 & Lisa's Kartoffel-Chips & 2.0 & 26.9 & 3.4 & 2062.0 \\
\hline KC_18 & Lisa's Kartoffel-Chips & 1.7 & 25.8 & 3.4 & 2067.0 \\
\hline KC_19 & Long Chips & 1.5 & 29.3 & 3.2 & 2246.0 \\
\hline \multicolumn{6}{|c|}{ Vegetable crisps } \\
\hline DC_15 & De Rit Organics & 1.6 & 30.0 & 2.6 & 2074.0 \\
\hline DC_16 & De Rit Organics & 1.9 & 36.2 & 2.9 & 1954.0 \\
\hline \multicolumn{6}{|c|}{ Wholegrain, crisp spelt snack } \\
\hline U_11 & Adazu Istie Cipsi & 2.2 & 21.0 & 1.0 & 2074.0 \\
\hline U_20 & Adazu Istie Cipsi & 3.0 & 21.0 & 1.0 & 2085.0 \\
\hline U_21 & Rosen Garten & 3.0 & 12.8 & 8.5 & 1726.0 \\
\hline U_22 & Rosen Garten & 5.0 & 15.8 & 10.3 & 1690.0 \\
\hline
\end{tabular}


content of crisps was $1 \mathrm{~mL} 0.1 M \mathrm{AgNO}_{3}=0.005844 \mathrm{~g}$ $\mathrm{NaCl}$ (Vardavas et al., 2007). In the article, the mean values from six measurements of each sample are given.

\section{Determination of sample crispness}

Texture analyser TA.HD plus (Stable Micro Systems, UK) was used for determination of sample crispness. For measuring a spherical probe was used; for even contact with probe samples were placed on the HDP/CFS (Crisp facture support). The test settings were: test speed $-1 \mathrm{~mm} \mathrm{~s}^{-1}$, trigger force $-0.049 \mathrm{~N}$ and distance $-3 \mathrm{~mm}$. Each kind of crisps was measured fifteen times to determine crispness. In the article, the mean values of peak force $(\mathrm{N})$ from all measurements of each sample are given.

\section{Determination of thickness}

Thickness of crisps samples was measured using an electronic digital outside micrometer (Conrad Electronic, Germany), range - 0-25.000 $\pm 0.001 \mathrm{~mm}$. Ten crisps of each sample at two random locations on the surface were measured. In the article, the mean values from all measurements of each sample are given.

\section{Determination of colour}

Objective crisps sample colour (CIE L*a* $\mathrm{b}^{*}$ ) measurement was carried out using a Tristimulus
Colorimeter (ColorTec Associates, Inc., USA). Crisps sample colour was measured for 10 crisps at three random locations on the surface of each sample. Colour values were recorded as $\mathrm{L} *$ - lightness, $\mathrm{a}^{*}$ redness or greenness, and $b^{*}$ - represents blueness or yellowness values (Liu et al., 2016). In the article, the mean values from all measurements of each sample are given.

\section{Statistical analysis}

All obtained results were processed by statistical methods - mean and standard deviations, Pearson correlations coefficient, hierarchical clusters. For interpretation of results, it was assumed that $p=0.05$ with credibility of $95 \%$ (significance was defined at $p$ $<0.05)$.

\section{Results and Discussion}

Crisps are the most popular products obtained from potatoes, but they are with high salt (2.0 -

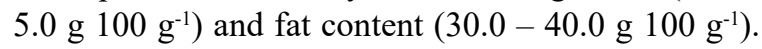
In Figure 1, summarised data (salt and fat content and energy value) from packaging labels about commercial potato and vegetable crisps and wholegrain snacks from Latvia market are presented.

Dendrogram (Figure 1) shows that samples can be divided into three clusters based on the information (salt and fat content and energy value) on their labels: the first cluster includes

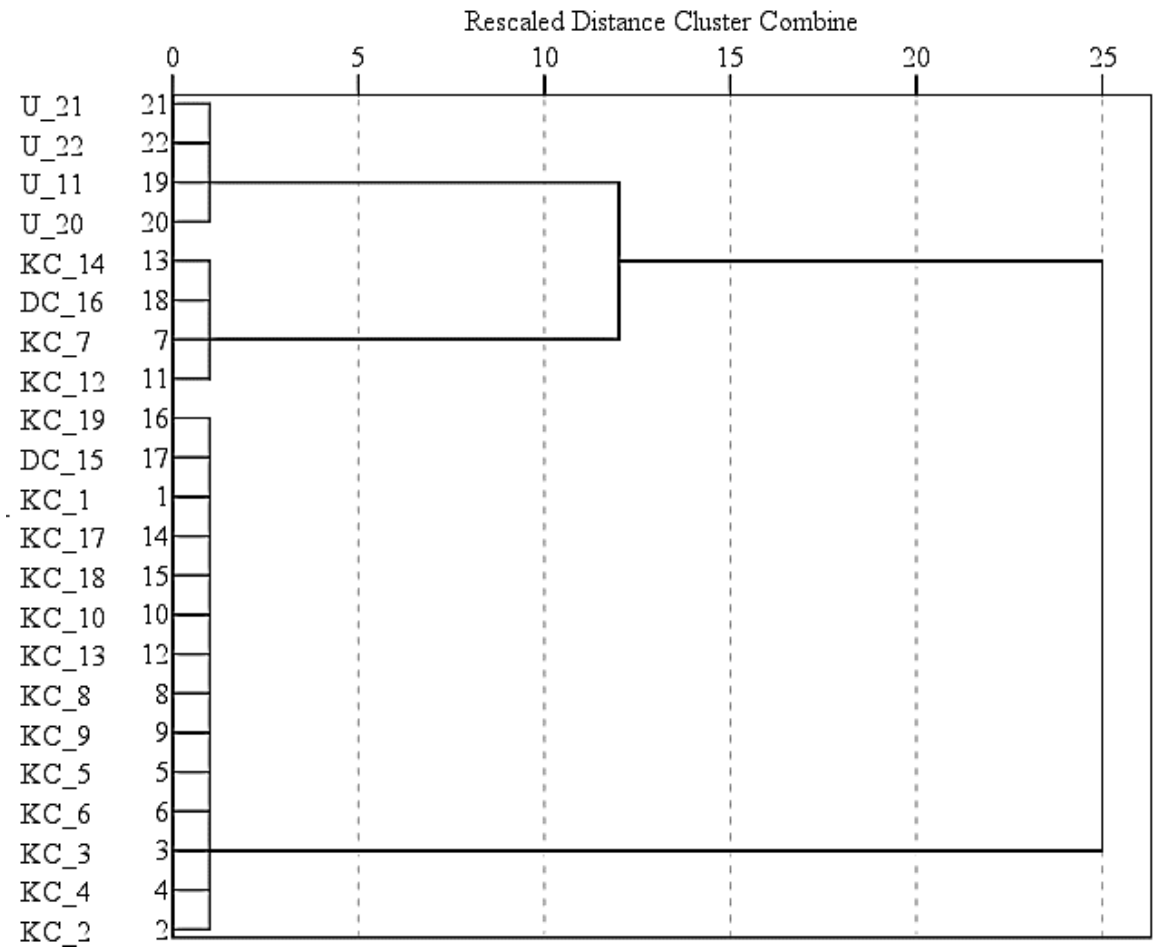

Figure 1. Division of analysed samples in clusters, based on their labels - salt, fat content and energy value. $\mathrm{KC}$ - potato crisps, DC - vegetable crisps, $\mathrm{U}$ - wholegrain, crisp spelt snacks. 
Determined and labelled salt content, $\mathrm{g} 100 \mathrm{~g}^{-1}$

\begin{tabular}{|c|c|c|c|}
\hline \multirow{2}{*}{ Sample } & \multicolumn{2}{|c|}{ Salt content, g $100 \mathrm{~g}^{-1}$} & \multirow{2}{*}{$\begin{array}{c}\text { Difference, } \\
\%\end{array}$} \\
\cline { 2 - 3 } & determined & labelled & \\
\hline KC_1 & $1.178 \pm 0.008$ & 1.000 & 17.80 \\
\hline KC_2 & $2.709 \pm 0.049$ & 2.000 & 35.45 \\
\hline KC_3 & $1.400 \pm 0.117$ & 1.400 & 0.00 \\
\hline KC_4 & $2.124 \pm 0.051$ & 2.000 & 6.20 \\
\hline KC_5 & $1.549 \pm 0.153$ & 1.600 & -3.19 \\
\hline KC_6 & $1.927 \pm 0.045$ & 1.800 & 7.06 \\
\hline KC_7 & $1.446 \pm 0.186$ & 1.500 & -3.60 \\
\hline KC_8 & $1.303 \pm 0.058$ & 1.200 & 8.58 \\
\hline KC_9 & $1.187 \pm 0.059$ & 1.400 & -15.21 \\
\hline KC_10 & $2.107 \pm 0.047$ & 1.900 & 10.89 \\
\hline KC_12 & $0.722 \pm 0.158$ & 2.000 & -63.90 \\
\hline
\end{tabular}

\begin{tabular}{|c|c|c|c|}
\hline \multirow{2}{*}{ Sample } & \multicolumn{2}{|c|}{ Salt content, $\mathrm{g} 100 \mathrm{~g}^{-1}$} & \multirow{2}{*}{$\begin{array}{c}\text { Difference, } \\
\%\end{array}$} \\
\cline { 2 - 3 } & determined & labelled & \\
\hline KC_13 & $1.469 \pm 0.064$ & 1.200 & 22.42 \\
\hline KC_14 & $1.203 \pm 0.041$ & 1.200 & 0.25 \\
\hline KC_17 & $2.209 \pm 0.140$ & 2.000 & 10.45 \\
\hline KC_18 & $1.152 \pm 0.128$ & 1.700 & -32.24 \\
\hline KC_19 & $1.951 \pm 0.079$ & 1.500 & 30.07 \\
\hline DC_15 & $1.514 \pm 0.081$ & 1.590 & -4.78 \\
\hline DC_16 & $1.720 \pm 0.090$ & 1.900 & -9.47 \\
\hline U_11 & $2.144 \pm 0.035$ & 2.200 & -2.55 \\
\hline U_20 & $3.820 \pm 0.216$ & 3.000 & 27.33 \\
\hline U_21 & $1.343 \pm 0.221$ & 3.000 & -55.23 \\
\hline U_22 & $5.289 \pm 0.062$ & 5.000 & 5.78 \\
\hline
\end{tabular}

$\mathrm{KC}$ - potato crisps, DC - vegetable crisps, $\mathrm{U}$ - wholegrain, crisp spelt snacks

14 samples, second cluster -4 samples, third cluster 4 samples.

In the first cluster, there are samples with

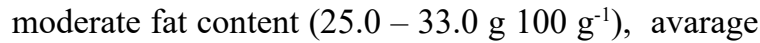

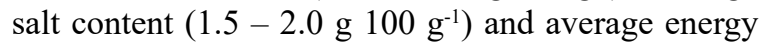

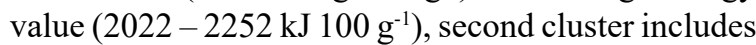

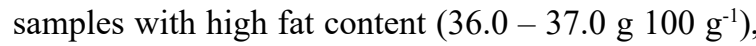

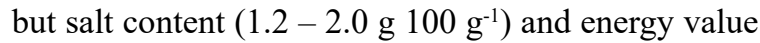
$\left(1964-2260 \mathrm{~kJ} 100 \mathrm{~g}^{-1}\right)$ are similar to the first cluster. In the third cluster, there are combined samples with

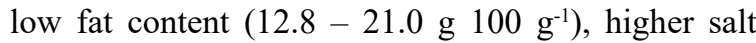

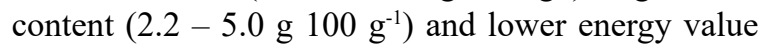

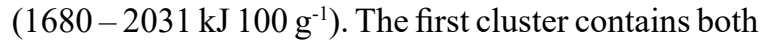
potato and vegetable crisps, just as the second cluster. Snack samples group does not really fit with crisps samples, and all four samples make the third cluster. As products from the third cluster show good results in low fat content and energy value, manufacturers should focus on salt content reduction in order to produce better and healthier product. Regarding potato and vegetable crisps, producers should pay attention to reducing fat content as first two clusters show higher values of fat and energy.

For more than million years our ancestors, like other mammals, ate food that contained less than $0.25 \mathrm{~g}$ of salt per day and, when there were discovered salt preservation properties, intake of salt considerably increased, and then again after invention and development of refrigerators and similar devices, salt intake started decreasing until recent decades (He \& MacGregor, 2009). A significant rise of highly salted food consumption like processed food, snacks, soft drinks etc., has led to an increase of salt intake (He \& MacGregor, 2009). In this research, the salt content of potato and vegetable crisps and wholegrain snacks was determined, and results were compared with information on the packaging label about salt content (Table 2). Analysing information on the potato and vegetable crisps labels, it was observed that salt

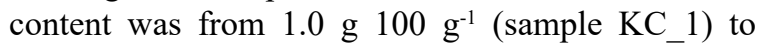

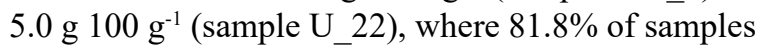

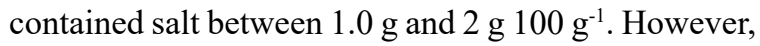
determined salt content was from $0.722 \pm 0.158 \mathrm{~g}$ $100 \mathrm{~g}^{-1}$ (samples KC_12) to $5.289 \pm 0.062{\mathrm{~g} 100 \mathrm{~g}^{-1} \text { for }}$ sample U_22 (Table 2).

A significant error limit of $5 \%$ considered that statistically is displayed as the first significant, thus it can be concluded that $31.8 \%$ of the investigated samples presented on label and determined salt content does not differ significantly $(\mathrm{p}>0.05)$. That means that $68.2 \%$ of the analysed potato and vegetable crisps on the packaging labels have represented incorrect salt content. For $22.7 \%$ of all analysed samples salt content was determined lower than indicated on packaging, the highest negative differences between measured and labelled salt content were for samples KC_12 (-63.9\%), where determined salt content was

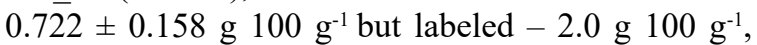
U_21 (-55.2\%) and DC_15 (-32.3\%). However, the significant positive differences were for samples KC_2 (35.4\%), where determined salt content was

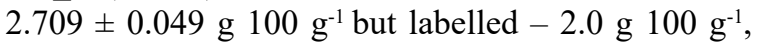
DC_16 (30.1\%) and U_20 (27.3\%). Results show that the highest salt content is for snacks' samples group

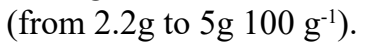

Nutrition information on food labels should promote consumer comprehension about food quality and it should encourage people make healthier choices, reduce salt intake, help identify and seek solutions to obesity problems (Cheftel, 2005). If a 


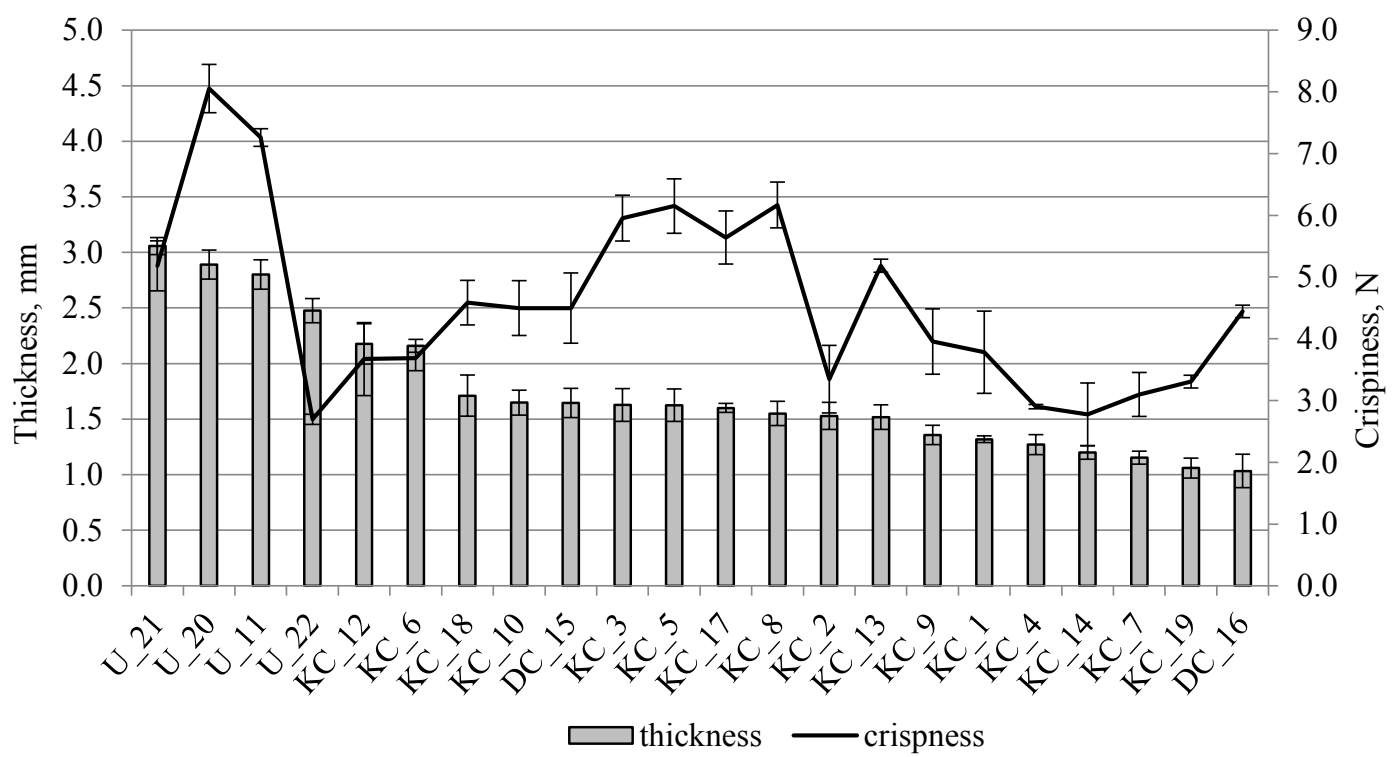

Figure 2. Thickness and crispness of analysed crisps samples.

$\mathrm{KC}$ - potato crisps, DC - vegetable crisps, $\mathrm{U}$ - wholegrain, crisp spelt snacks.

person consumes $100 \mathrm{~g}$ of salty snacks a day, then salt intake is already more than 7 times higher than evolutionary intake of WHO suggested salt intake amount (less than $5 \mathrm{~g}$ ). If a person eats $100 \mathrm{~g}$ of $\mathrm{KC}_{-} 1$ sample crisps, salt intake by crisps would make $20 \%$ of total daily intake of salt, whereas if a person eats $100 \mathrm{~g}$ of U_22 samples, then salt intake would make 100\% of suggested daily intake only by snack consumption. Salty snacks typically contain a lot of salt and, it is essentially important to find ways to decrease amount of it. Even if there are consumed crisps with low salt content, it still makes a large part of recommended daily amount of salt.

Crisps are a very good example of consumer acceptance reasons, as in this case consumer relies more on texture than flavour (Rojo \& Vincent, 2009). That is why there have been different researches with the aim to determine crispness, factors, which impact it, and measurement possibilities. As crispness is one of key causes that defines consumer's choice, food producers need to develop their recipes and technologies in order to deliver product that meets consumer expectations. The most important for the producer is to choose appropriate variety of raw product (potato, vegetable variety). Regarding potato crisps, it is confirmed that texture mainly depends on starch contents of potato tubers and after that on the sum of nitrogen substances and non-starch polysaccharides (Kita, 2002).

There was measured thickness and crispness (hardness) of all samples (Figure 2). Results show that the thickest samples were revealed in the snack group (U_21, U_20, U_11 and U_22), from 2.48 to $3.06 \mathrm{~mm}$, the crisps were thinner than snacks - from
1.03 to $2.18 \mathrm{~mm}$, and the thickest were samples $\mathrm{KC} \_12(2.18 \mathrm{~mm})$ and $\mathrm{KC} \_6(2.16 \mathrm{~mm})$, while the thinnest samples were $\mathrm{DC}_{-} \overline{16}(1.03 \mathrm{~mm})$ and $\mathrm{KC}_{-} 19$ $(1.06 \mathrm{~mm})$. Although vegetable crisps sample was the thinnest, fat content for this exact sample is second highest. For better combination of product quality indicators, manufacturers should reassess their technological process in order to improve finished product. The hardest samples also mainly were from the snack group - U_20 $(8.1 \mathrm{~N}), \mathrm{U}_{-} 11(7.3 \mathrm{~N})$ and then $\mathrm{KC}_{-} 8(6.2 \mathrm{~N})$, but the most fragile samples were U_22 $(2.7 \mathrm{~N}), \mathrm{KC}_{-} 14(2.8 \mathrm{~N})$ and $\mathrm{KC}_{-} 4$ $(2.9 \mathrm{~N})$. It can be explained by the number of different producers (together 13 brands for 22 samples), where every manufacturer has their own recipe, ingredient's proportion, selected oil, varieties of raw materials and production process special nuances and parameters.

Average crispness for potato crisps was $4.3 \mathrm{~N}$, for vegetable crisps $-4.5 \mathrm{~N}$ and for snacks $-5.8 \mathrm{~N}$. If mean values are compared by product groups, then the hardest are snacks, while potato and vegetable crisps have more similar results.

Positive moderate correlation between thickness and crispness, $r=0.489(\mathrm{p}<0.05)$, which means positive moderate correlation was found out. This result confirms that these indicators are connected, but this connection does not have high correlation level.

The first thing consumers evaluate when choosing a food product is its colour, one of the most important characteristics, which is often also connected with the notion of quality. Table 3 represents colour values of the potato and vegetable crisps samples.

Value $\mathrm{L}^{*}$ of the potato crisps colour component, characterising the light and dark colour nuances of the 
Characterization of potato and vegetable crisps colour

\begin{tabular}{|c|c|c|c|}
\hline \multirow{2}{*}{ Samples } & \multicolumn{3}{|c|}{ Colour value } \\
\hline & $\mathrm{L}^{*}$ & $a^{*}$ & $b^{*}$ \\
\hline KC_1 & $71.34 \pm 1.34$ & $-5.80 \pm 1.29$ & $24.35 \pm 1.15$ \\
\hline $\mathrm{KC} \_2$ & $60.39 \pm 4.97$ & $-2.87 \pm 1.19$ & $18.48 \pm 2.90$ \\
\hline $\mathrm{KC} \_3$ & $62.18 \pm 5.99$ & $-4.81 \pm 1.59$ & $28.44 \pm 3.14$ \\
\hline $\mathrm{KC} \_4$ & $60.61 \pm 5.66$ & $-6.40 \pm 4.14$ & $26.21 \pm 1.53$ \\
\hline $\mathrm{KC} \_5$ & $63.82 \pm 3.68$ & $-5.20 \pm 1.06$ & $23.11 \pm 2.36$ \\
\hline KC_6 & $70.02 \pm 2.13$ & $-6.51 \pm 1.02$ & $28.40 \pm 1.89$ \\
\hline $\mathrm{KC} \_7$ & $71.20 \pm 2.16$ & $-7.76 \pm 1.63$ & $26.27 \pm 3.91$ \\
\hline $\mathrm{KC} \_8$ & $67.24 \pm 1.26$ & $-5.04 \pm 1.61$ & $24.60 \pm 1.35$ \\
\hline KC_9 & $68.75 \pm 1.50$ & $-6.54 \pm 1.84$ & $17.22 \pm 3.61$ \\
\hline KC_10 & $63.56 \pm 4.33$ & $-6.56 \pm 1.92$ & $28.13 \pm 3.03$ \\
\hline KC_12 & $60.25 \pm 5.90$ & $-5.40 \pm 1.40$ & $29.55 \pm 5.99$ \\
\hline KC_13 & $61.24 \pm 4.61$ & $-4.54 \pm 1.94$ & $22.94 \pm 4.24$ \\
\hline KC_14 & $67.69 \pm 5.84$ & $-5.08 \pm 1.12$ & $27.38 \pm 4.51$ \\
\hline KC_17 & $60.34 \pm 5.25$ & $-6.50 \pm 1.80$ & $24.55 \pm 3.11$ \\
\hline KC_18 & $55.84 \pm 4.71$ & $-1.62 \pm 0.27$ & $24.12 \pm 6.64$ \\
\hline KC_19 & $79.42 \pm 1.38$ & $-4.68 \pm 0.40$ & $23.22 \pm 1.75$ \\
\hline DC_15 & $20.60 \pm 3.99$ & $5.56 \pm 1.61$ & $-1.16 \pm 0.77$ \\
\hline DC_16 & $39.40 \pm 5.43$ & $5.10 \pm 1.48$ & $22.40 \pm 6.94$ \\
\hline U_11 & $50.24 \pm 5.24$ & $0.43 \pm 0.11$ & $22.50 \pm 5.97$ \\
\hline U_20 & $52.25 \pm 5.14$ & $1.12 \pm 1.01$ & $17.67 \pm 5.41$ \\
\hline U_21 & $40.32 \pm 0.59$ & $16.49 \pm 0.85$ & $9.85 \pm 1.38$ \\
\hline U_22 & $56.83 \pm 1.35$ & $-0.51 \pm 0.76$ & $20.37 \pm 1.03$ \\
\hline
\end{tabular}

samples, varies from $55.84 \pm 4.71$ (sample KC_18) to $79.42 \pm 1.38$ (sample KC_19). KC_18 samples have darker results in terms of colour, as these were crisps with tomato flavour, thus the colour $\mathrm{L}^{*}$ and $\mathrm{a}^{*}$ values stand out. For potato crisps $\mathrm{b}^{*}$ values are between $17.22 \pm 3.61$ (sample KC_9) and $29.55 \pm$ 5.99 (sample $\mathrm{KC} \mathrm{12}$ ), which means that the colour of the samples is light yellow. Both vegetable crisps samples are different from each other regarding $b^{*}$ and $\mathrm{L}^{*}$ colour values, but have similar values for $a^{*}$ colour value. DC_15 vegetable crisps were from beetroot, which explains low L* value $(20.60 \pm 3.99)$ and also other two colour indicators, which points out dark red colour, while DC_16 contained vegetables like carrots, potatoes and beetroots and that accords to results that these samples are between yellow and red. Snack samples do not have significant differences $(p>0.05)$ in the colour values; the results are similar, except the sample U_21, which has different values for all three colour indicators, and it has a solid explanation, as the sample's U_21 one of ingredients is beetroot concentrate (13\%).

\section{Conclusions}

All analysed samples can be divided into three clusters, based on the information (salt and fat content and energy value) on their labels: the first cluster includes samples with moderate fat content, average salt content and average energy value, second cluster - samples with high fat content, average salt content and energy value similar to first cluster, third cluster - samples with low fat content, higher salt content and lower energy value. The first cluster contains both potato and vegetable crisps, just as the second cluster, while the third cluster includes snack samples. For $31.8 \%$ of the investigated samples, information presented on label and determined salt content does not differ significantly $(\mathrm{p}>0.05)$. That means that $68.2 \%$ of the analysed potato and vegetable crisps and wholegrain snacks on the packaging labels have represented incorrect salt content.

Positive moderate correlation $(r=0.489)$ between potato and vegetable crisps thickness and crispness was found out. 
Potato crisps, vegetable crisps and snacks colour affects the used raw materials - carrots, potatoes and beetroots or other.

\section{Acknowledgements}

Research has been supported by the National research programme 'Agricultural Resources for
Sustainable Production of Qualitative and Healthy Foods in Latvia' (AgroBioRes) (2014 - 2017), project No. 4 'Sustainable use of local agricultural resources for qualitative and healthy food product development' (FOOD).

\section{References}

1. Bibbins-Domingo, K., Chertow, G.M., Coxson, P.G., Moran, A., Lightwood, J.M., Pletcher, M.J., \& Goldman, L. (2010). Projected effect of dietary salt reductions on future cardiovascular disease. The New England Journal of Medicine, 362, 590 - 599. DOI: 10:1056/NEJMoa0907355.

2. Cheftel, J.C. (2005). Food and nutrition labelling in the European Union. Food Chemistry, 93(3), 531 550. DOI: 10.1016/j.foodchem.2004.11.041.

3. Grunert, K.G., Wills, J.M., \& Fernández-Celemín, L. (2010). Nutrition knowledge, and use and understanding of nutrition information on food labels among consumers in the UK. Appetite, 55(2), 177 189. DOI: $10.1016 /$ j.appet.2010.05.045.

4. He, F.J., \& MacGregor, G.A. (2009). A comprehensive review on salt and health and current experience of worldwide salt reduction programmes. Journal of Human Hypertension, 23(6), 363 - 384. DOI: 10.1038/ jhh.2008.144.

5. Kita, A. (2002). The influence of potato chemical composition on crisp texture. Food Chemistry, 76(2), 173 - 179. DOI: 10.1016/S0308-8146(01)00260-6.

6. Kita, A., Lisińska, G., \& Gołubowska, G. (2007). The effects of oils and frying temperatures on the texture and fat content of potato crisps. Food Chemistry, 102(1), 1 - 5. DOI: 10.1016/j.foodchem.2005.08.038.

7. Liu, C., Liu, W., Lu, X., Chen, W., Yang, J., \& Zheng, L. (2016). Potential of multispectral imaging for realtime determination of colour change and moisture distribution in carrot slices during hot air dehydration. Food Chemistry, 195, 110 - 116. DOI: 10.1016/j.foodchem.2015.04.145.

8. Mendoza, F., Dejmek, P., \& Aguilera, J.M. (2007). Colour and image texture analysis in classification of commercial potato chips. Food Research International, 40(9), 1146 - 1154. DOI: 10.1016/j. foodres.2007.06.014.

9. Mohr Method (1981) Pearsons chemical analysis of foods (8th ed.) (p. 13). England: Longman Scientific \& Technical.

10. Mueller, E., Koehler, P., \& Scherf, K.A. (2016). Applicability of salt reduction strategies in pizza crust. Food Chemistry, 192, 1116 - 1123. DOI: 10.1016/j.foodchem.2015.07.066.

11. Pedreschi, F., Segnini, S., \& Dejmek, P. (2004). Evaluation of the texture of fried potatoes. Journal of Texture Studies, 35(3), 277 - 291. DOI: 10.1103/PhysRevB.75.235432.

12. Rojo, F.J., \& Vincent, J.F.V. (2009). Objective and subjective measurement of the crispness of crisps from four potato varieties. Engineering Failure Analysis, 16(8), 2698 - 2704. DOI: 10.1016/j. engfailanal.2009.04.033.

13. Romani, S., Rocculi, P., Mendoza, F., \& Dalla Rosa, M. (2009). Image characterization of potato chip appearance during frying. Journal of Food Engineering, 93(4), 487 - 494. DOI: 10.1016/j. jfoodeng.2009.02.017.

14. Roudaut, G., Dacremont, C., Valles Pamies, B., Colas, B., \& Le Meste, M. (2002). Crispness: A critical review on sensory and material science approaches. Trends in Food Science and Technology, 13(6-7), 217 - 227. DOI: 10.1016/S0924-2244(02)00139-5.

15. Salvador, A., Varela, P., Sanz, T., \& Fiszman, S.M. (2009). Understanding potato chips crispy texture by simultaneous fracture and acoustic measurements, and sensory analysis. LWT - Food Science and Technology, 42(3), 763 - 767. DOI: 10.1016/j.lwt.2008.09.016.

16. Taniwaki, M., \& Kohyama, K. (2012). Mechanical and acoustic evaluation of potato chip crispness using a versatile texture analyzer. Journal of Food Engineering, 112(4), 268 - 273. DOI: 10.1016/j. jfoodeng.2012.05.015.

17. Vardavas, C.I., Yiannopoulos, S., Kiriakakis, M., Poulli, E., \& Kafatos, A. (2006). Fatty acid and salt contents of snacks in the Cretan and Cypriot market: A child and adolescent dietary hazard. Food Chemistry, 101(3), 924 - 931. DOI: 10.1016/j.foodchem.2006.02.042.

18. Vincent, J.F.V. (1998). The quantification of crispness. Journal of science food agriculture, $78,162-168$.

19. WHO (2012). WHO Guideline: Sodium intake for adults and children. World Health Organization (WHO), Geneva. 